Article

\title{
Fabrication and Characterizations of Hot-Melt Extruded Nanocomposites Based on Zinc Sulfate Monohydrate and Soluplus
}

\author{
Song Yi Lee ${ }^{1,+}$, Suyeong Nam ${ }^{1,+}$, Yohan Choi ${ }^{2}$, Minju Kim ${ }^{2}$, Ja Seong Koo ${ }^{1}$, Byung-Jo Chae ${ }^{2}$, \\ Wie-Soo Kang ${ }^{3}$ and Hyun-Jong Cho ${ }^{1, *}$ \\ 1 College of Pharmacy, Kangwon National University, Chuncheon, Gangwon 24341, Korea; \\ heymush@kangwon.ac.kr (S.Y.L.); swim@kangwon.ac.kr (S.N.); rnwkrnrn@gmail.com (J.S.K.) \\ 2 Department of Animal Resources Science, College of Animal Life Sciences, Kangwon National University, \\ Chuncheon, Gangwon 24341, Korea; cyh6150@hanmail.net (Y.C.); mandoo3333@hanmail.net (M.K.); \\ bjchae@kangwon.ac.kr (B.-J.C.) \\ 3 School of Bioscience and Biotechnology, Kangwon National University, Chuncheon, Gangwon 24341, Korea; \\ kangwiso@kangwon.ac.kr \\ * Correspondence: hjcho@kangwon.ac.kr; Tel.: +82-33-250-6916 \\ $\dagger$ These authors equally contributed to this work.
}

Received: 20 July 2017; Accepted: 1 September 2017; Published: 4 September 2017

\begin{abstract}
Zinc sulfate monohydrate $\left(\mathrm{ZnSO}_{4}\right)$-loaded nanocomposites (NCs) were fabricated by using a hot-melt extruder (HME) system. Soluplus (SP) was adopted as an amphiphilic polymer matrix for $\mathrm{HME}$ processing. The micro-size of $\mathrm{ZnSO}_{4}$ dispersion was reduced to nano-size by $\mathrm{HME}$ processing with the use of SP. $\mathrm{ZnSO}_{4}$ could be homogeneously dispersed in SP through HME processing. $\mathrm{ZnSO}_{4} / \mathrm{SP}$ NCs with a $75 \mathrm{~nm}$ mean diameter, a 0.1 polydispersity index, and a $-1 \mathrm{mV}$ zeta potential value were prepared. The physicochemical properties of $\mathrm{ZnSO}_{4} / \mathrm{SP} N C s$ and the existence of SP in $\mathrm{ZnSO}_{4} / \mathrm{SP} N C s$ were further investigated by solid-state studies. Nano-size range of $\mathrm{ZnSO}_{4} / \mathrm{SP}$ NC dispersion was maintained in the simulated gastrointestinal environments ( $\mathrm{pH} 1.2$ and 6.8 media). No severe toxicity in intestinal epithelium after oral administration of $\mathrm{ZnSO}_{4} / \mathrm{SP} N C s$ (at $100 \mathrm{mg} / \mathrm{kg}$ dose of $\mathrm{ZnSO}_{4}$, single dosing) was observed in rats. These results imply that developed $\mathrm{ZnSO}_{4} / \mathrm{SP}$ $\mathrm{NC}$ can be used as a promising nano-sized zinc supplement formulation. In addition, developed HME technology can be widely applied to fabricate nanoformulations of inorganic materials.
\end{abstract}

Keywords: hot-melt extrusion; nanocomposite; Soluplus; zinc sulfate monohydrate

\section{Introduction}

Zinc ( $\mathrm{Zn})$ is one of dietary micronutrients and it is second highest trace element in the body [1]. Over $95 \%$ of $\mathrm{Zn}$ is located in the cells, but its dominant storage site is absent in the body [1]. There are three physiological roles of $\mathrm{Zn}$ : catalytic, structural, and regulatory activities [1]. Zn is known to be primarily absorbed in the duodenum and jejunum via transporters [2]. Its absorption may be reduced by phytate, fiber, and iron, but improved by citric acid [3,4]. Homeostasis of $\mathrm{Zn}$ concentrations in cell and plasma is maintained by the regulation of absorption, excretion, and retention $[1,5]$. Deficiency of Zn may result in anorexia, dysgeusia, dysosmia, skin rash, infection, alopecia, growth failure, and impaired wound healing [1]. Therefore, adequate supplementation of $\mathrm{Zn}$ is very important to maintain normal physiological conditions. Several oral formulations (i.e., tablet and capsule) of $\mathrm{ZnSO}_{4}$ are already commercially available. Nevertheless, there has been a little progress in the development of pharmaceutical dosage forms of $\mathrm{ZnSO}_{4}$. Especially, there are a few reports regarding the development of nanoformulations of $\mathrm{ZnSO}_{4}$ for oral administration. The barriers in the absorption process of $\mathrm{ZnSO}_{4}$ can be overcome by the introduction of nano-sized formulation. 
Inorganic crystals, metals, and salts may be classified into lyophobic materials. Their affinity to solvents (i.e., water) is very low; thus, thermodynamic work is necessary for dispersing those materials in solvents. Diverse preparation methods have been developed for the development of nano-sized particles of metal [6]. HME is a continuous manufacturing process that can be easily scaled up [7]. Materials can be thrown into the extruder, moved towards the die and homogeneously blended by rotating screws, and extruded from the die (or an orifice) [8-11]. During the HME process, the temperature of barrels is designed above the glass transition temperature $\left(\mathrm{T}_{\mathrm{g}}\right)$ and sometimes over the melting temperature $\left(\mathrm{T}_{\mathrm{m}}\right)$ of polymeric substances, and the drug can be molecularly dispersed in the polymer matrix $[9,12,13]$.

Soluplus (SP) was used as the main polymer matrix for HME processing in this investigation. $\mathrm{SP}$ is a grafted polymer composed of polyethylene glycol, polyvinylcaprolactam, and polyvinylacetate, so it has an amphiphilic characteristic. It has white to yellowish granules, and its molecular weight is $\sim 118,000 \mathrm{~g} / \mathrm{mol}$. It can be used as a binder, a solubilizer, a film-former, and a stabilizer. Of note, it has been widely used as a main matrix for the production of HME formulations due to its thermodynamic properties [14,15]. Conclusively, the use of SP in HME processing can improve solubility and the bioavailability of poorly water-soluble drugs $[9,14,16,17]$. So far, the HME technique has been used principally to make solid dispersions of organic molecules, which have low molecular weight and poor water solubility, with appropriate polymers (i.e., cellulose derivatives, poly (ethylene-co-vinyl acetate), polyethylene glycol, polyvinylpyrrolidone, and SP) $[9,14,16,18]$. Herein, $\mathrm{ZnSO}_{4} / \mathrm{SP}$ nanocomposites (NCs) were fabricated by HME processing, and their physicochemical and biosafe properties were investigated.

\section{Materials and Methods}

\subsection{Materials}

$\mathrm{ZnSO}_{4} \cdot \mathrm{H}_{2} \mathrm{O}$ was purchased from TMC Co., Ltd. (Anyang, Korea). SP was kindly gifted from BASF (Ludwigshafen, Germany). All other reagents were of analytical grade and were purchased from commercial sources.

\subsection{Preparation and Particle Characterizations of $\mathrm{ZnSO}_{4} / S P$ NCs}

$\mathrm{ZnSO}_{4}$ and SP $(3: 7, w / w)$ were blended prior to the extrusion and they were put into the extruder at a $50 \mathrm{~g} / \mathrm{min}$ rate. These mixtures were processed by a twin-screw hot-melt extruder (STS-25HS, Hankook E.M. Ltd., Pyeongtaek, Korea) equipped with a round-shaped die (2 $\mathrm{mm}$ diameter). The temperature of the barrels was maintained as shown in Figure 1, and the speed of the screw was set at $200 \mathrm{rpm}$. Extrudates were cooled down to room temperature and milled by the HBL-3500S grinder (Samyang Electronics Co., Gunpo, Korea) for pulverization. The particle characteristics of dispersion of $\mathrm{ZnSO}_{4} / \mathrm{SP} \mathrm{NCs}$, at $10 \mathrm{mg} / \mathrm{mL}$ concentration, in distilled water (DW), pH 1.2 medium, and pH 6.8 buffer were assessed. Simulated gastric fluid (pH 1.2) was prepared by dissolving $\mathrm{NaCl}(2.0 \mathrm{~g})$ and $\mathrm{HCl}(7.0 \mathrm{~mL})$ in $\mathrm{DW}(1000 \mathrm{~mL}$ final volume). In the case of simulated intestinal fluid (pH 6.8), $0.02 \mathrm{~mol} / \mathrm{L} \mathrm{KH}_{2} \mathrm{PO}_{4}$ in DW (250 mL) and $0.2 \mathrm{~mol} / \mathrm{L} \mathrm{NaOH}(118 \mathrm{~mL})$ were mixed, and DW was added to attain a $1000 \mathrm{~mL}$ final volume. The mean diameter, polydispersity index, and zeta potential values of $\mathrm{ZnSO}_{4} / \mathrm{SP} N C s$ in DW, $\mathrm{pH} 1.2$ medium, and $\mathrm{pH} 6.8$ buffer were measured using dynamic light scattering (DLS) and laser Doppler methods (ELS-Z1000; Otsuka Electronics, Tokyo, Japan) according to the manufacturer's instructions. The morphological shapes of $\mathrm{ZnSO}_{4} / \mathrm{SP}$ NCs in DW, pH 1.2 medium, and pH 6.8 buffer were observed by transmission electron microscopy (TEM). The aliquot of dispersion was stained with $2 \%(w / v)$ phosphotungstic acid. It was placed on copper grids with films, dried for $10 \mathrm{~min}$, and observed by TEM (JEM 1010; JEOL, Tokyo, Japan). The content of $\mathrm{Zn}$ in $\mathrm{ZnSO}_{4} / \mathrm{SP}$ NCs was measured by inductively coupled plasma-optical emission spectrometry (ICP-OES; Optima 7300 DV, PerkinElmer, Inc., Waltham, MA, USA). ZnSO 4 /SP NCs were dissolved in nitric acid and processed with microwave digestion. 


\subsection{X-ray Diffractometry (XRD) Analysis}

XRD analysis of $\mathrm{ZnSO}_{4}$, SP, and $\mathrm{ZnSO}_{4} / \mathrm{SP}$ NCs was performed with a Philips X'Pert PRO MPD diffractometer (PANalytical Corp., Almero, The Netherlands) with a copper source (1.54 $\AA$ ). Start and end positions of $2 \theta$ were $10^{\circ}$ and $70^{\circ}$. The step size and scan step time were $0.013^{\circ}$ and $8.67 \mathrm{~s}$. Generator conditions were set at $30 \mathrm{~mA}$ and $40 \mathrm{kV}$.

\subsection{X-ray Photoelectron Spectroscopy (XPS) Assay}

The chemical compositions of the outer layers in $\mathrm{ZnSO}_{4}, \mathrm{SP}$, and $\mathrm{ZnSO}_{4} / \mathrm{SP}$ NCs were measured by XPS (K-Alpha ${ }^{\mathrm{TM}_{+}}$, Thermo Fisher Scientific, East Grinstead, UK) in the Central Laboratory of Kangwon National University. XPS analysis was performed for measuring the atomic concentrations of $\mathrm{Zn} 2 \mathrm{p}, \mathrm{O} 1 \mathrm{~s}, \mathrm{~N} 1 \mathrm{~s}, \mathrm{C} 1 \mathrm{~s}, \mathrm{Cl} 2 \mathrm{p}$, and S 2p in $\mathrm{ZnSO}_{4}, \mathrm{SP}$, and $\mathrm{ZnSO}_{4} / \mathrm{SP}$ NCs. The spot size was $400 \mu \mathrm{m}$.

\subsection{Fourier-Transform Infrared (FT-IR) Analysis}

FT-IR spectra of $\mathrm{ZnSO}_{4}, \mathrm{SP}$, and $\mathrm{ZnSO}_{4} / \mathrm{SP}$ NCs were obtained using a Frontier ${ }^{\mathrm{TM}}$ FT-IR spectrometer (PerkinElmer Inc., Buckinghamshire, UK) with the attenuated total reflectance (ATR) mode. Transmittance (\%) of each group was scanned in a range from 400 to $4000 \mathrm{~cm}^{-1}$.

\subsection{Stability Test of NCs}

The stability of developed $\mathrm{ZnSO}_{4} / \mathrm{SP}$ NCs $(10 \mathrm{mg} / \mathrm{mL})$ in different media (DW, $\mathrm{pH} 1.2$, and $\mathrm{pH}$ 6.8) was assessed by measuring the hydrodynamic size of NCs. After incubating for $2 \mathrm{~h}$ and $6 \mathrm{~h}$ at each medium in the shaking incubator (with a $50 \mathrm{rpm}$ speed) at $37^{\circ} \mathrm{C}$, the mean diameters of $\mathrm{ZnSO}_{4} / \mathrm{SP}$ NCs were measured by the DLS method (ELS-Z1000; Otsuka Electronics) according to the manufacturer's protocol.

\subsection{Toxicity Test of NCS}

In vivo toxicity test of developed formulation was tested in male Sprague-Dawley rats (250 $\pm 5 \mathrm{~g}$ of body weight; Orient Bio, Seongnam, Korea). The rats were reared in a light-controlled room with $22 \pm 2{ }^{\circ} \mathrm{C}$ temperature and $55 \pm 5 \%$ relative humidity. The experimental protocol of an animal study was approved by the Animal Care and Use Committee of Kangwon National University. The toxicity of HME formulations against the intestinal epithelium was tested by histological staining. Dispersion of $\mathrm{ZnSO}_{4}$ or $\mathrm{ZnSO}_{4} / \mathrm{SP} \mathrm{NCs}$, at $100 \mathrm{mg} / \mathrm{kg} \mathrm{ZnSO}$ dose, in DW was orally administered to SD rats. Those rats were sacrificed $6 \mathrm{~h}$ after oral administration and the jejunum was dissected. The dissected tissues were fixed in $4 \%(v / v)$ formaldehyde solution for one day. Then, they were washed with DW, dehydrated in alcohols, and embedded in paraffin. Paraffinized tissues were sliced at a 5-10 $\mu \mathrm{m}$ thickness and stained with hematoxylin and eosin (H\&E) reagent. They were observed via optical microscopy to evaluate the toxicity of the developed formulation.

\subsection{Data Analyses}

Statistical analyses of data were performed with analysis of variance (ANOVA) by using SPSS Statistics for Windows (version 23.0 SPSS Inc., Chicago, IL, USA). All experiments were repeated at least thrice. Data are shown as the mean \pm standard deviation (SD).

\section{Results and Discussion}

\subsection{Preparation and Particle Characterizations of $\mathrm{ZnSO}_{4} / \mathrm{SP} N C S$}

In this study, the homogeneous dispersion of inorganic molecules (e.g., $\mathrm{ZnSO}_{4}$ ) in SP by HME processing with twin screws was prepared. A twin screw extruder, compared to single screw extruder, provides the following advantages: a higher dispersibility, easier feeding, a lower risk of overheating, higher process productivity, and a better modulation of process parameters $[9,19,20]$. 
Strong forces produced by twin screw systems can disperse $\mathrm{ZnSO}_{4}$ homogeneously in an SP matrix and HME processing with SP can reduce the surface energy and prevent the occurrence of aggregates. Compared to micro-size particles of $\mathrm{ZnSO}_{4}$, nano-sized particles of $\mathrm{ZnSO}_{4}$ have the following advantages: the feasibility of intravenous administration, efficient cellular entry, and improved absorption across the mucosal membrane. HME has been used for preparing solid dispersion formulations of active pharmaceutical ingredients $[9,21]$. Molecular dispersing during the HME process can transform the crystalline property of the drug to an amorphous state, and it may contribute to the improvement of dissolution and bioavailability of the drug $[9,13,14,22]$. In addition, HME processing of a hydrophilic drug can provide taste masking of the drug $[9,23]$. Although HME formulations of organic substances have been widely developed, there are a few reports regarding the inorganic materials-based carriers prepared by HME processing [24].

The mean diameter of $\mathrm{ZnSO}_{4}$ dispersion in DW was greater than $5 \mu \mathrm{m}$ in this study. In this investigation, SP was used as a polymer matrix (host), so its feeding content was designed to be higher than $\mathrm{ZnSO}_{4}$ (guest molecule). In our preliminary study, the mean diameters of formulations with several weight ratios between $\mathrm{ZnSO}_{4}$ and SP were measured. The suggested ratio $\left(\mathrm{ZnSO}_{4}: \mathrm{SP}=3: 7\right)$ was finally selected due to the smallest mean diameter of the prepared NC dispersion. It is expected that nano-sized carriers can improve the cellular entry and mucosal permeability of $\mathrm{ZnSO}_{4}$. $\mathrm{HME}$ has been applied to prepare nanocarriers of $\mathrm{ZnSO}_{4}$ in this investigation. The rotating screws force $\mathrm{ZnSO}_{4}$ and SP towards the die, and those materials can be blended homogeneously and softened during the extrusion process (Figure 1). Pressure and heat during the HME process can disperse $\mathrm{ZnSO}_{4}$ molecules homogeneously in SP. The amphiphilic property of SP might contribute to the fabrication of nano-sized $\mathrm{ZnSO}_{4}$ particles. After the HME process, the extrudate was further pulverized and dispersed in aqueous media. As shown in Table 1, the mean diameter of $\mathrm{ZnSO}_{4} / \mathrm{SP}$ NC dispersion in DW was $75 \mathrm{~nm}$. Considering its polydispersity index value $(0.10 \pm 0.01)$, it can be concluded that the size distribution of NC dispersion is narrow. The zeta potential value of $\mathrm{ZnSO}_{4} / \mathrm{SP} N C$ dispersion in DW was close to zero. A similar mean diameter of $\mathrm{ZnSO}_{4} / \mathrm{SP}$ NCs was observed at $\mathrm{pH} 1.2$, while a small portion of aggregates has been formed at $\mathrm{pH} 6.8$ (Figure 2A). The polydispersity index values of $\mathrm{ZnSO}_{4} / \mathrm{SP} N C s$ at pH 1.2 and 6.8 were $0.04 \pm 0.01$ and $0.17 \pm 0.01$, respectively. They indicate the narrow size distribution of $\mathrm{ZnSO}_{4} / \mathrm{SP} \mathrm{NC}$ dispersion at $\mathrm{pH} 1.2$ and 6.8. The round shape of $\mathrm{ZnSO}_{4} / \mathrm{SP}$ NCs was also presented in TEM images (Figure 2B). The content of $\mathrm{Zn}$ in $\mathrm{ZnSO}{ }_{4} / \mathrm{SP} \mathrm{NCs}_{\text {, }}$ measured by ICP-OES, was $11.44 \pm 0.55 \%$, and its entrapment efficiency in NCs was approximately $100 \%$. This implies that $\mathrm{ZnSO}_{4}$ was successfully incorporated in the NCs during the HME process.

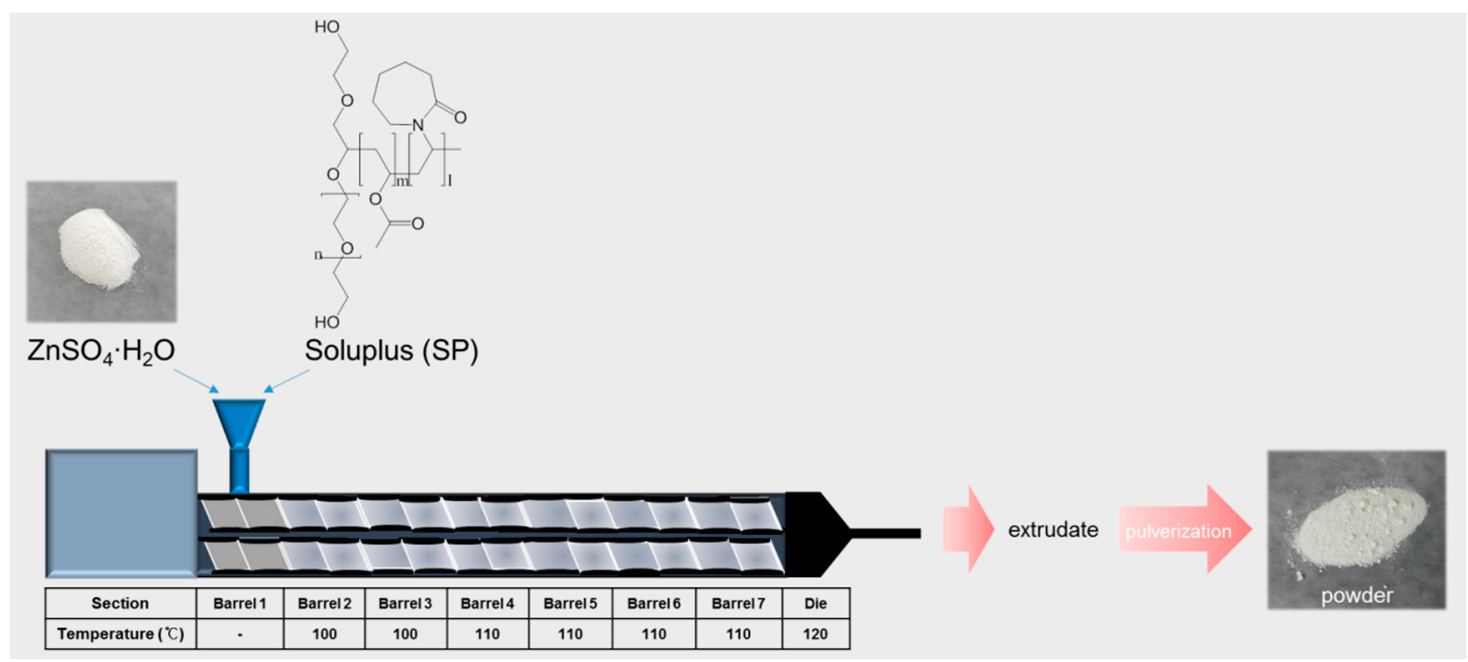

Figure 1. Schematic illustration of the HME process for the development of $\mathrm{ZnSO}_{4} / \mathrm{SP} \mathrm{NC}$ formulation. 
Table 1. Particle characterization of $\mathrm{ZnSO}_{4} / \mathrm{SP} \mathrm{NCs}(n \geq 3)$.

\begin{tabular}{cccc}
\hline Formulation & Mean Diameter (nm) & Polydispersity Index & Zeta Potential (mV) \\
\hline $\mathrm{ZnSO}_{4}$ /SP NCs & $75 \pm 2$ & $0.10 \pm 0.01$ & $-1.0 \pm 1.3$ \\
\hline
\end{tabular}

(A)

DW

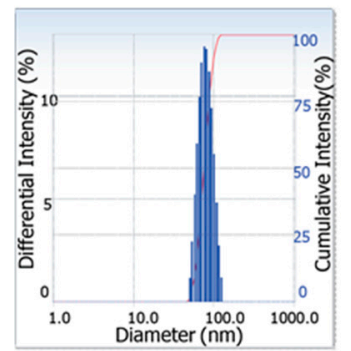

(B)

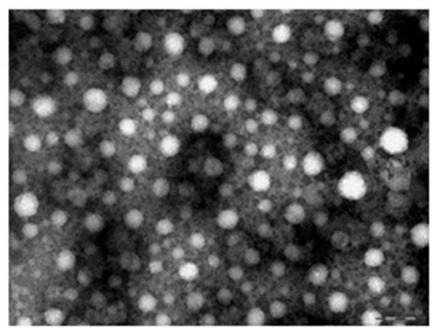

$\mathrm{pH} 1.2$
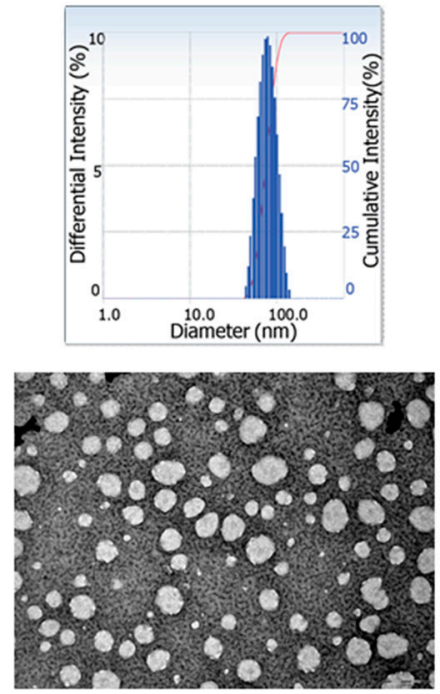

$\mathrm{pH} 6.8$
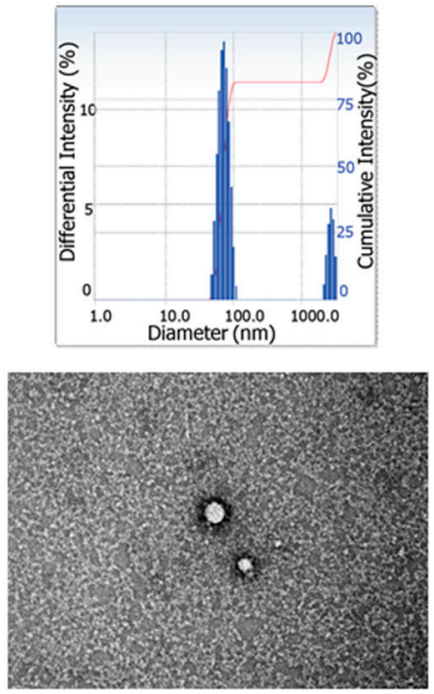

Figure 2. Particle characterization of $\mathrm{ZnSO}_{4} / \mathrm{SP}$ NCs dispersion. (A) Particle size distribution and (B) TEM images of $\mathrm{ZnSO}_{4} / \mathrm{SP}$ NCs in distilled water (DW), pH 1.2 medium, and pH 6.8 buffer are presented. The length of scale bar in the TEM image is $200 \mathrm{~nm}$.

\subsection{Solid-State Studies}

The dispersion of $\mathrm{ZnSO}_{4}$ in SP was investigated by XRD analysis (Figure 3). Multiple sharp peaks are shown in the profile of $\mathrm{ZnSO}_{4}$, implying its crystalline property. On the contrary, sharp peaks were hardly shown in the XRD pattern of SP, as reported in our previous study [14]. This may suggest the amorphous property of SP, which would coincide with our previous result [14]. The broad peak of SP at $70{ }^{\circ} \mathrm{C}$, observed via differential scanning calorimetry, implies the transition of SP from a glassy to a rubbery state [14]. The intensity of sharp peaks in the $\mathrm{ZnSO}_{4} / \mathrm{SP} \mathrm{NC}$ group, compared with that of $\mathrm{ZnSO}_{4}$, was attenuated.

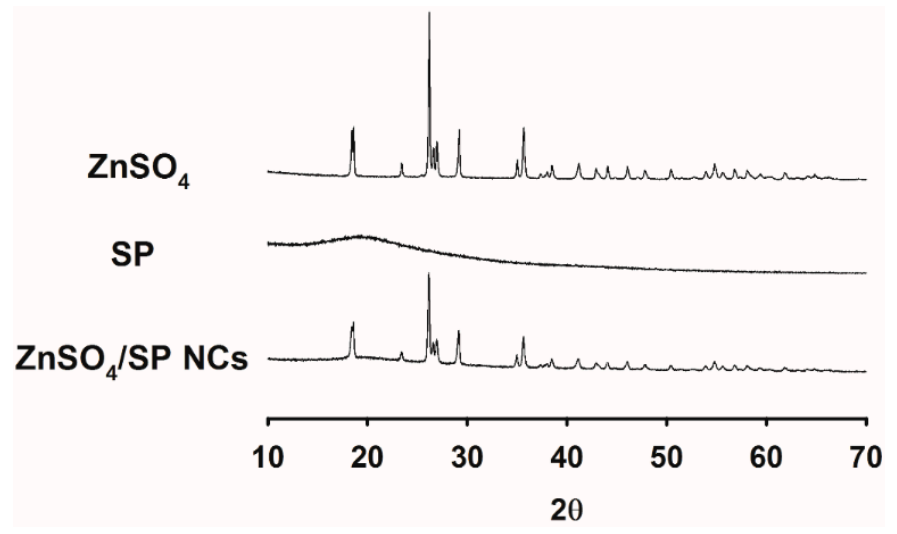

Figure 3. $\mathrm{XRD}$ profiles of $\mathrm{ZnSO}_{4}, \mathrm{SP}$, and $\mathrm{ZnSO}_{4} / \mathrm{SP}$ NCs. Counts values according to $2 \theta$ are plotted.

The dispersion of $\mathrm{ZnSO}_{4}$ in SP was verified by XPS analysis (Figure 4). Chemical compositions in the outer layers (generally top 0 to $10 \mathrm{~nm}$ ) of tested materials can be determined via XPS analysis. 
As shown in Figure 4A, the atomic portion of $\mathrm{Zn} 2 \mathrm{p}$ in $\mathrm{ZnSO}_{4}$ was $12.76 \%$. The peaks of S 2p and O $1 \mathrm{~s}$ also indicated the presence of an $\mathrm{SO}_{4}{ }^{2-}$ ion. The atomic percentages of $\mathrm{C} 1 \mathrm{~s}, \mathrm{~N} 1 \mathrm{~s}$, and $\mathrm{O} 1 \mathrm{~s}$ in $\mathrm{SP}$ were $67.29 \%, 0.51 \%$, and $32.20 \%$, respectively (Figure $4 \mathrm{~B}$ ). In the $\mathrm{ZnSO}_{4} / \mathrm{SP} \mathrm{NC}$ group (Figure $4 \mathrm{C}$ ), the contents of $\mathrm{Zn} 2 \mathrm{p}$ and S $2 \mathrm{p}$ were reduced to $0.61 \%$ and $0.66 \%$, respectively. A dramatic decrease in the atomic percentages of $\mathrm{Zn} 2 \mathrm{p}$ and S 2p in $\mathrm{ZnSO}_{4} / \mathrm{SP} \mathrm{NCs}$, compared with those in $\mathrm{ZnSO}_{4}$, indicates the presence of SP molecules in $\mathrm{ZnSO}_{4} / \mathrm{SP}$ NCs. The C 1 s composition of $\mathrm{ZnSO}_{4} / \mathrm{SP}$ NCs $(73.21 \%)$ was close to that of SP $(67.29 \%)$, rather than that of $\mathrm{ZnSO}_{4}(28.81 \%)$. This means that SP may be located on the outer surface of $\mathrm{ZnSO}_{4} / \mathrm{SP} \mathrm{NCs}$. $\mathrm{Cl} 2 \mathrm{p}$ in $\mathrm{ZnSO}_{4}$ can be regarded as impurities. Its absence in the profile of $\mathrm{ZnSO}_{4} / \mathrm{SP}$ NCs implies the incorporation of $\mathrm{ZnSO}_{4}$ in NCs.
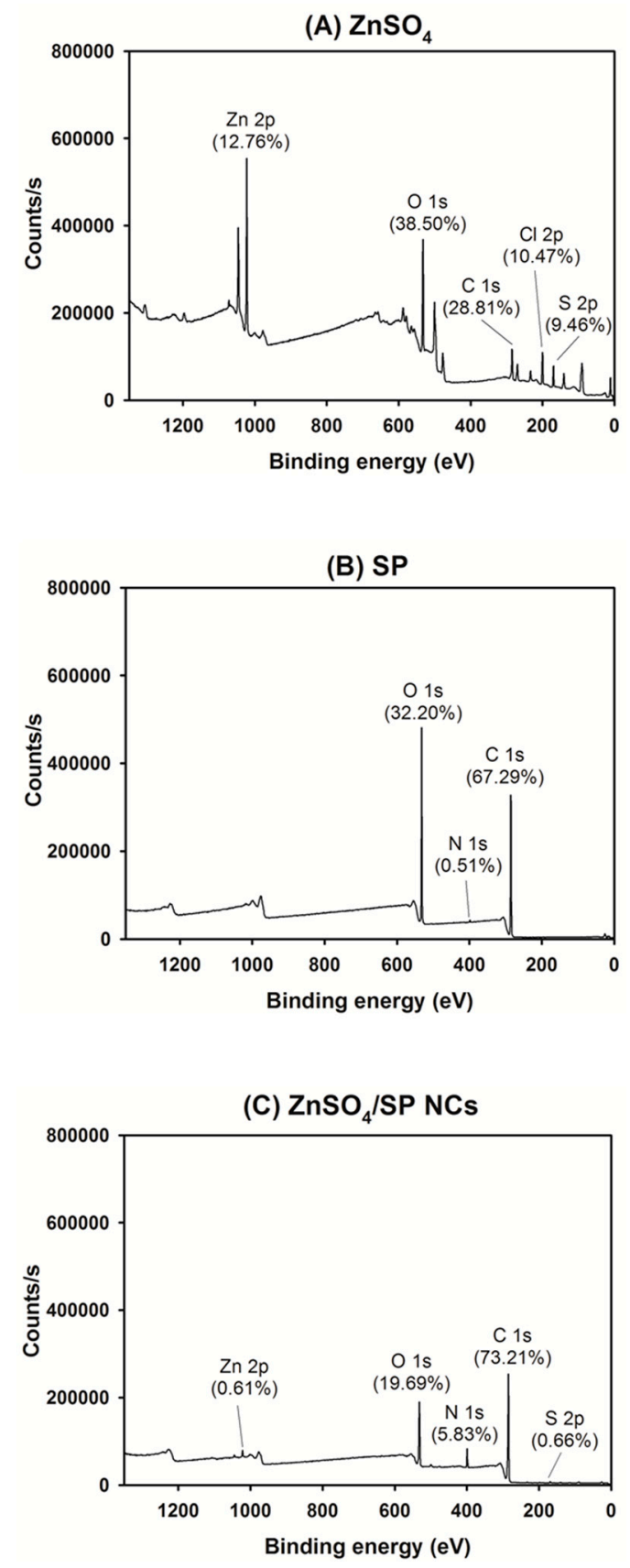

Figure 4. XPS profiles of (A) $\mathrm{ZnSO}_{4}$, (B) SP, and (C) $\mathrm{ZnSO}_{4} / \mathrm{SP}$ NCs. Counts/s according to binding energy is plotted. The atomic percentage is shown in the graph. 
The fabrication of $\mathrm{ZnSO}_{4} / \mathrm{SP}$ NCs was identified via FT-IR analysis (Figure 5). A free $\mathrm{SO}_{4}{ }^{2-}$ ion has four fundamental vibrations $\left(v_{1}, v_{2}, v_{3}\right.$, and $\left.v_{4}\right)$, and corresponding peaks have been observed in the spectrum of $\mathrm{ZnSO}_{4}$ as reported [25]. Additionally, the broad band at $3117 \mathrm{~cm}^{-1}$ may be due to the stretching mode of the water molecules. The carbonyl bands in the spectrum of SP were shown between 1800 and $1400 \mathrm{~cm}^{-1}$. The peak at $1732 \mathrm{~cm}^{-1}$ indicates $\mathrm{OCOCH}_{3}$ or the ester group, and the other peak at $1628 \mathrm{~cm}^{-1}$ means $\mathrm{CON}$ or amide group. Although these two peaks are shown in the spectrum of $\mathrm{ZnSO}_{4} / \mathrm{SP}$ NCs, the wavenumber $\left(\mathrm{cm}^{-1}\right)$ and transmittance (\%) of those peaks were slightly altered. This implies the dispersion of $\mathrm{ZnSO}_{4}$ in SP by the HME process.

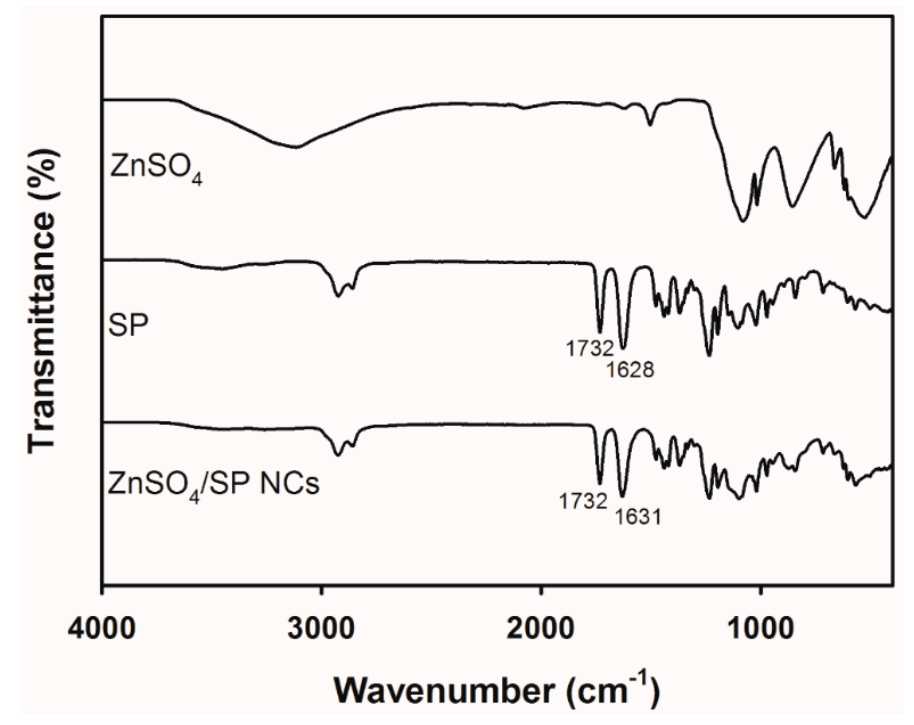

Figure 5. FT-IR spectra of $\mathrm{ZnSO}_{4}, \mathrm{SP}$, and $\mathrm{ZnSO}_{4} / \mathrm{SP}$ NCs. Transmittance according to the wavenumber is shown.

\subsection{Stability of NCS}

The in vitro stability of the developed $\mathrm{ZnSO}_{4} / \mathrm{SP}$ NCs was evaluated in DW, a pH 1.2 medium, and a $\mathrm{pH} 6.8$ buffer (Figure 6). The amphiphilic property of SP can be attributed to the homogeneous dispersion of $\mathrm{ZnSO}_{4}$ in the aqueous medium. However, the presence of salts and enzymes and the variable $\mathrm{pH}$ values can affect the stabilization and maintenance of NC dispersion. Generally, the media of $\mathrm{pH} 1.2$ and 6.8 are used to indicate artificial gastric and intestinal environment in disintegration and dissolution studies. The structural stability of fabricated $\mathrm{ZnSO}_{4} / \mathrm{SP} \mathrm{NCs}$ was estimated by measuring their mean diameters after incubation in each medium. As shown in Figure 6, the mean diameter was not altered, even after incubation for $6 \mathrm{~h}$ in DW and $\mathrm{pH} 1.2$ medium. In the $\mathrm{pH} 6.8$ buffer, the mean diameter of $\mathrm{ZnSO}_{4} / \mathrm{SP}$ NCs was higher than those in DW and the $\mathrm{pH} 1.2$ medium at $0 \mathrm{~h}(p<0.05)$. However, it was reduced to approximately $100 \mathrm{~nm}$ after incubation for $6 \mathrm{~h}$. The zeta potential values of $\mathrm{ZnSO}_{4}$ /SP NC dispersion in DW, the $\mathrm{pH} 1.2$ medium, and $\mathrm{pH} 6.8$ buffer were $-1.0 \pm 1.3$ (Table 1 ), $43.8 \pm 6.3$, and $-3.0 \pm 0.2 \mathrm{mV}$, respectively. In acidic $\mathrm{pH}$, a more positive zeta potential value was exhibited. Pharmaceutical salts (i.e., phosphate salts) included in a $\mathrm{pH} 6.8$ buffer may interact with $\mathrm{ZnSO}_{4}$ and/or SP, and the aggregation of NCs seems to be induced by that interaction. However, its influence was weakened as the incubation time went by. Although the initial mean diameter of $\mathrm{ZnSO}_{4} / \mathrm{SP} \mathrm{NCs}$ in the $\mathrm{pH} 6.8$ buffer (at $0 \mathrm{~h}$ ) was approximately $224 \mathrm{~nm}$, this value can be also regarded as suitable for the mucosal delivery as a nanocarrier. The polydispersity index values of $\mathrm{ZnSO}_{4} / \mathrm{SP}$ NC dispersion in DW, the $\mathrm{pH} 1.2$ medium, and the $\mathrm{pH} 6.8$ buffer after $6 \mathrm{~h}$ incubation were $0.14 \pm 0.04$, $0.09 \pm 0.04$, and $0.15 \pm 0.04$, respectively. Those values indicate the maintenance of a narrow size distribution of NCs after $6 \mathrm{~h}$ of incubation. The maintenance of the nano-size of the developed NCs in 
the $\mathrm{pH} 1.2$ and $\mathrm{pH} 6.8$ media can contribute to the improved delivery to the intestinal epithelium after oral administration.

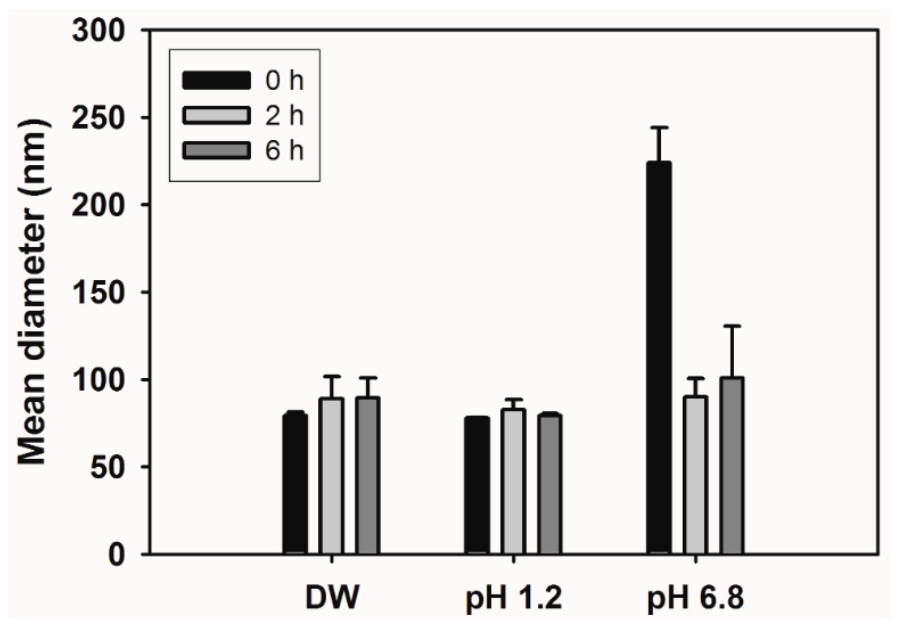

Figure 6. Hydrodynamic size of $\mathrm{ZnSO}_{4}$ /SP NCs in DW, a pH 1.2 medium, and a pH 6.8 buffer after incubating for $6 \mathrm{~h}$. Each point indicates the mean \pm standard deviation (SD) $(n=3)$.

\subsection{Intestinal Toxicity of NCs}

The intestinal toxicity of developed HME-processed NCs was assessed in rats after oral administration. The jejunum was stained with H\&E reagent to test the epithelium toxicity (Figure 7). It was reported that zinc can modify the tight junctions and change the barrier roles in the epithelial monolayers of the intestine [26]. Additionally, in relatively high $\mathrm{Zn}$ concentrations, it may show cytotoxicity to intestinal cells by apoptosis and other mechanisms [27]. In this study, the administration dose for an acute toxicity test was determined considering the maintenance of a nano-size of NC dispersion. As shown in Figure 7, there was no significant difference in the morphology of epithelium between $\mathrm{ZnSO}_{4}$ and $\mathrm{ZnSO}_{4} / \mathrm{SP}$ NCs. It is expected that acute toxicity is absent in the intestinal epithelium after single dosing. Amphiphilic SP can decrease the surface tension during the fabrication of NCs, and it may help to reduce the hydrodynamic size of NCs. However, the toxicity of SP should also be considered for the development of $\mathrm{ZnSO}_{4} / \mathrm{SP} N C$ s. According to the manufacturer's data (BASF SE, Ludwigshafen, Germany), the oral $\mathrm{LD}_{50}$ value of $\mathrm{SP}$ was reported to be greater than $5 \mathrm{~g} / \mathrm{kg}$ [14]. Considering the $\mathrm{LD}_{50}$ value, $\mathrm{SP}$ can be used safely at the current administration dose. Both the dispersibility and safety of $\mathrm{ZnSO}_{4} / \mathrm{SP}$ NCs indicate successful in vivo application.

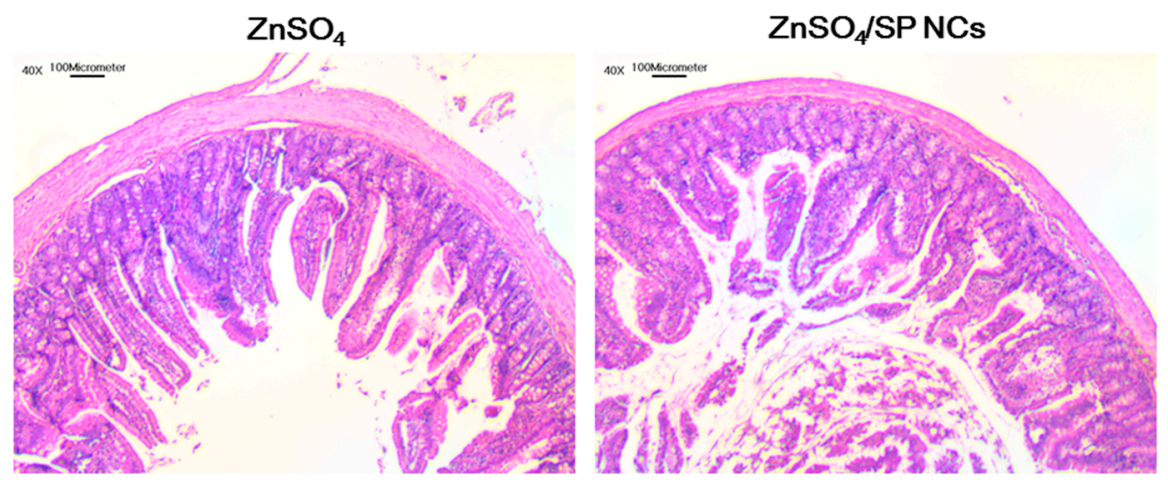

Figure 7. H\&E staining results of $\mathrm{ZnSO}_{4}$ and $\mathrm{ZnSO}_{4} / \mathrm{SP}$ NC-treated groups. The length of the scale bar in the image is $100 \mu \mathrm{m}$. 


\section{Conclusions}

The HME-processed NC formulation of $\mathrm{ZnSO}_{4}$ was fabricated and its physicochemical properties were investigated. The micron-sized dispersion of $\mathrm{ZnSO}_{4}$ was reduced to nano-sized dispersion by $\mathrm{HME}$ processing. $\mathrm{ZnSO}_{4}$ seemed to be homogeneously dispersed in SP (used as an inert matrix), and $\mathrm{ZnSO}_{4} / \mathrm{SP}$ NCs with a $75 \mathrm{~nm}$ mean diameter, a 0.1 polydispersity index, and a $-1 \mathrm{mV}$ zeta potential value were fabricated. The dispersion of $\mathrm{ZnSO}_{4}$ in SP was further identified via XRD, XPS, and FT-IR analyses. The hydrodynamic size of the $\mathrm{ZnSO}_{4} / \mathrm{SP} N C$ dispersion was constant for $6 \mathrm{~h}$ in DW, implying the maintenance of the stability of nano-sized particles. In rats, the oral administration of $\mathrm{ZnSO}_{4} / \mathrm{SP}$ NCs did not induce severe toxicity against the intestinal epithelium. All of these findings suggest that the developed zinc NC formulation can be used efficiently and safely for in vivo application.

Acknowledgments: This work was supported by Korea Institute of Planning and Evaluation for Technology in Food, Agriculture, Forestry and Fisheries (IPET) through Agri-Bio industry Technology Development Program, funded by Ministry of Agriculture, Food and Rural Affairs (MAFRA) (No. 116073-03-2-CG000).

Author Contributions: Wie-Soo Kang, Byung-Jo Chae and Hyun-Jong Cho conceived and designed the experiments; Song Yi Lee, Suyeong Nam, Yohan Choi, Minju Kim, Ja Seong Koo and Wie-Soo Kang performed the experiments; Song Yi Lee, Suyeong Nam, Wie-Soo Kang and Hyun-Jong Cho analyzed the data; and Hyun-Jong Cho wrote the paper.

Conflicts of Interest: The authors declare no conflict of interest.

\section{References}

1. Livingstone, C. Zinc: Physiology, deficiency, and parenteral nutrition. Nutr. Clin. Pract. 2015, 30, 371-382. [CrossRef] [PubMed]

2. Turnlund, J.R.; King, J.C.; Keyes, W.R.; Gong, B.; Michel, M.C. A stable isotope study of zinc absorption in young men: Effects of phytate and alpha-cellulose. Am. J. Clin. Nutr. 1984, 40, 1071-1077. [PubMed]

3. Cousins, R.J. Absorption, transport and hepatic metabolism of copper and zinc: Special reference to metallothionein and ceruloplasmin. Physiol. Rev. 1985, 65, 238-309. [PubMed]

4. Kenny, F.; Sriram, K.; Hammond, J. Clinical zinc deficiency during adequate enteral nutrition. J. Am. Coll. Nutr. 1989, 8, 83-85. [CrossRef] [PubMed]

5. Hambidge, M.; Krebs, N.F. Interrelationships of key variables of human zinc homeostasis: Relevance to dietary zinc requirements. Ann. Rev. Nutr. 2001, 21, 429-452. [CrossRef] [PubMed]

6. Rao, C.N.R.; Matte, H.R.; Voggu, R.; Govindaraj, A. Recent progress in the synthesis of inorganic nanoparticles. Dalton Trans. 2012, 41, 5089-5120. [CrossRef] [PubMed]

7. Maniruzzaman, M.; Nokhodchi, A. Continuous manufacturing via hot-melt extrusion and scale up: Regulatory matters. Drug Discov. Today 2017, 22, 340-351. [CrossRef] [PubMed]

8. Hwang, I.; Kang, C.Y.; Park, J.B. Advances in hot-melt extrusion technology toward pharmaceutical objectives. J. Pharm. Investig. 2017, 47, 123-132. [CrossRef]

9. Patil, H.; Tiwari, R.V.; Repka, M.A. Hot-melt extrusion: From theory to application in pharmaceutical formulation. AAPS PharmSciTech 2016, 17, 20-42. [CrossRef] [PubMed]

10. Piao, J.; Lee, J.Y.; Weon, J.B.; Ma, C.J.; Ko, H.J.; Kim, D.D.; Kang, W.S.; Cho, H.J. Angelica gigas Nakai and Soluplus-based solid formulations prepared by hot-melting extrusion: Oral absorption enhancing and memory ameliorating effects. PLoS ONE 2015, 10, e0124447. [CrossRef] [PubMed]

11. Stanković, M.; Frijlink, H.W.; Hinrichs, W.L. Polymeric formulations for drug release prepared by hot melt extrusion: Application and characterization. Drug Discov. Today 2015, 20, 812-823. [CrossRef] [PubMed]

12. Jaiswar, D.R.; Jha, D.; Amin, P.D. Preparation and characterizations of stable amorphous solid solution of azithromycin by hot melt extrusion. J. Pharm. Investig. 2016, 46, 655-668. [CrossRef]

13. Lang, B.; McGinity, J.W.; Williams, R.O. Hot-melt extrusion-Basic principles and pharmaceutical applications. Drug Dev. Ind. Pharm. 2014, 40, 1133-1155. [CrossRef] [PubMed]

14. Lee, J.Y.; Kang, W.S.; Piao, J.; Yoon, I.S.; Kim, D.D.; Cho, H.J. Soluplus ${ }^{\circledR} /$ TPGS-based solid dispersions prepared by hot-melt extrusion equipped with twin-screw systems for enhancing oral bioavailability of valsartan. Drug Des. Dev. Ther. 2015, 9, 2745-2756. 
15. Lu, J.; Cuellar, K.; Hammer, N.I.; Jo, S.; Gryczke, A.; Kolter, K.; Langley, N.; Repka, M.A. Solid-state characterization of Felodipine-Soluplus amorphous solid dispersions. Drug Dev. Ind. Pharm. 2016, 42, 485-496. [CrossRef] [PubMed]

16. Thiry, J.; Kok, M.G.; Collard, L.; Frère, A.; Krier, F.; Fillet, M.; Evrard, B. Bioavailability enhancement of itraconazole-based solid dispersions produced by hot melt extrusion in the framework of the Three Rs rule. Eur. J. Pharm. Sci. 2017, 99, 1-8. [CrossRef] [PubMed]

17. Zhang, Y.; Liu, Y.; Luo, Y.; Yao, Q.; Zhong, Y.; Tian, B.; Tang, X. Extruded Soluplus/SIM as an oral delivery system: Characterization, interactions, in vitro and in vivo evaluations. Drug Deliv. 2016, 23, 1902-1911. [PubMed]

18. Han, S.D.; Jung, S.W.; Jang, S.W.; Jung, H.J.; Son, M.; Kim, B.M.; Kang, M.J. Preparation of solid dispersion of dronedarone hydrochloride with Soluplus ${ }^{\circledR}$ by hot melt extrusion technique for enhanced drug release. Chem. Pharm. Bull. 2015, 63, 295-299. [CrossRef] [PubMed]

19. Crowley, M.M.; Zhang, F.; Repka, M.A.; Thumma, S.; Upadhye, S.B.; Battu, S.K.; McGinity, J.W.; Martin, C. Pharmaceutical applications of hot-melt extrusion: Part I. Drug Dev. Ind. Pharm. 2007, 33, 909-926. [CrossRef] [PubMed]

20. Lee, H.L.; Vasoya, J.M.; Cirqueira, M.L.; Yeh, K.L.; Lee, T.; Serajuddin, A.T. Continuous preparation of 1:1 haloperidol-maleic acid salt by a novel solvent-free method using a twin screw melt extruder. Mol. Pharm. 2017, 14, 1278-1291. [CrossRef] [PubMed]

21. Zhang, S.; Meng, X.; Wang, Z.; Fan, A.; Wang, G.; Zhao, Y.; Tang, Y. Engineering hot-melt extruded solid dispersion for controlled release of hydrophilic drugs. Eur. J. Pharm. Sci. 2017, 100, 109-115. [CrossRef] [PubMed]

22. Jones, D.S.; Tian, Y.; Li, S.; Yu, T.; Abu-Diak, O.A.; Andrews, G.P. The use of binary polymeric networks in stabilizing polyethylene oxide solid dispersions. J. Pharm. Sci. 2016, 105, 3064-3072. [CrossRef] [PubMed]

23. McGinity, J.W.; Zhang, F.; Koleng, J.; Repka, M. Hot-melt extrusion as a pharmaceutical process. Am. Pharm. Rev. 2001, 4, 25-37.

24. Wahl, P.R.; Treffer, D.; Mohr, S.; Roblegg, E.; Koscher, G.; Khinast, J.G. Inline monitoring and a PAT strategy for pharmaceutical hot melt extrusion. Int. J. Pharm. 2013, 455, 159-168. [CrossRef] [PubMed]

25. Sivanesan, G.; Kolandaivel, P.; Selvasekarapandian, S. Laser Raman and FT-IR studies of pure and Zn-doped TGS. Mater. Chem. Phys. 1993, 34, 73-77. [CrossRef]

26. Wang, X.; Valenzano, M.C.; Mercado, J.M.; Zurbach, E.P.; Mullin, J.M. Zinc supplementation modifies tight junctions and alters barrier function of CACO-2 human intestinal epithelial layers. Dig. Dis. Sci. 2013, 58, 77-87. [CrossRef] [PubMed]

27. Zödl, B.; Zeiner, M.; Sargazi, M.; Roberts, N.B.; Marktl, W.; Steffan, I.; Ekmekcioglu, C. Toxic and biochemical effects of zinc in Caco-2 cells. J. Inorg. Biochem. 2003, 97, 324-330. [CrossRef] 